\title{
Creationism in confusion?
}

SIR- - It was, perhaps, too much to expect the founders of the "Association for the Protection of Evolution"' (APE) to give an objective report on the recent Biblical Creation Society (BCS) conference at High Leigh (News and Views, 25 October, p.703). What is surprising, however, is that you should give such extensive and uncritical exposure to views which were selfevidently biased.

The very heading to your report, "Creationism in confusion", betrays a tendentious purpose, namely to present BCS in the worst possible light. Evey difference of opinion or continuing debate among creationists is represented as evidence of "confusion" rather than the product of honest enquiry and developing ideas. By the same token, would the APE-men agree that evolutionary theory is "in confusion" because neo-darwinians, punctuated equilibraists and reformed cladists disagree? Debate and disagreement is the stuff of scientific and intellectual progress and the BCS open day demonstrated that (contrary to the impression given) creationists are capable of constructive self-criticism at the highest scientific and theological level.

The conference report contains several serious errors of understanding. Howgate and Lewis fail to grasp the purpose of David Tyler's lecture which was not to reinterpret geology in terms of catastrophism but to illustrate from field observations (1) that the straitjacket of Lyellian uniformitarianism is a hindrance to the science of geology and (2) that there is a need to test the appropriateness of modern analogues, whether catastrophic or non-catastrophic.

Dr Darnborough, described as "BCS's top geneticist"' is, in fact, a molecular biologist. He does not "believe in evolution". His paper argued, rather, that the operation of accepted evolutionary processes at the molecular level upon genetically perfect created organisms would lead to a living world with genetic characteristics essentially similar to those observed in modern organisms. This paradigm is fully consistent with both the scientifically observed facts and the biblical doctrines of creation and the fall. It further avoids the need to invoke the vast improbabilities of chemical evolution.

My own lecture "Christ and the Cosmos" is represented as a "keynote theological policy statement" and a condemnation of "American creationists". It was nothing of the kind. It was a positive exposition of an important New Testament passage which sets out the relationship between Christ and the created, divorcing "creationism" from the Creator, and illustrated this by reference to certain trends in American creationism. To suggest that I "condemned" or "attacked" the whole US creationist movement is so far from the truth that I am tempted to attribute to your reporters the unworthy motive of using your journal to sow international discord among creationists.

The report continues with the statement that "a stalwart of the rival creationist organization the Creation Science Movement attcked the backsliding into theism of the BCS". First, there is no rivalry between BCS and CSM. The two societies have somewhat different aims but remain in close and amicable consultation. Second, your correspondents should learn a few basic theological terms before venturing into print on such subjects. Both BCS and CSM are proud to be "theists". It is "deism"' that we, equally, disown.

Finally, we are astonished that you should include, as part of the conference report, a private conversation over tea between one of the APE representatives and Dr David Gower. The ethical lapse is the more serious since Dr Gower is seriously misreported as admitting "unenthusiastically" that he ascribed genetic defects to the fall and that sexual communication by pheromones has to do with "lustful temptations". These serious misrepresentations of a senior university academic are, to say the least, deplorable.

What your correspondents fail to grasp is that creationism is an holistic philosophy which seeks to understand the scientific enterprise within a biblical and theological framework. In pursuing this concept, and rejecting the arid materialism which underlies so much modern thinking, we are simply returning to the paradigm espoused by such as Newton, Boyle, Kelvin, Faraday and Maxwell, who among others laid the foundations of science as we know it.

E.H. ANDREWS

Department of Materials,

Queen Mary College,

Mile End Road, London EI 4NS, UK

\section{Riposte on CERN}

SIR - Victor F. Weisskopf and J. H. Mulvey (Nature 8 October, pp.599-600) make various criticisms of our study of CERN, the European laboratory for particle physics. The criticisms are unfortunately misplaced since they relate to a brief Nature article (6 September, p.4) rather than to the detailed findings recently published in two parts in Research Policy.

First, we do not base our "main conclusions on a selection of so-called 'crucial' experiments" - we actually devote as much attention to evaluating "incremental" contributions to science. Indeed, the very first conclusion listed in the second of our papers is that since 1970 , "the overall record of the CERN machines taken together has been better than that of the accelerators at any other laboratory in the world when judged in terms of experiments producing precise measurements". Nowhere do we describe such work as "dull physics".
Second, Mulvey's assertion that there is no evidence to support our conclusion that the multinational nature of CERN has previously led to problems in research management is wholly inaccurate. Even the most cursory reading of our papers would reveal that our evidence comes from interviews with more than 180 high-energy physicists, many of whom cited this particular problem as important.

Third, it is gross oversimplification by Mulvey to suggest that the greater success of the United States in terms of important discoveries was due to a single machine. The Brookhaven Alternating Gradient Synchrotron had a far better record than the very similar CERN Proton Synchrotron, as did Fermilab compared with the CERN Super Proton Synchrotron (SPS), while the CERN Intersecting Storage Rings " "missed" several major discoveries in their energy range.

Fourth, the successes of Stanford with the SPEAR collider were not entirely unpredictable. Among other factors, they can be attributed partly to the fact that the machine opened up a new energy range (unlike the CERN SPS which began operating four years after an identical energy US machine), and partly to its users, who already boasted an impressive track record in exploiting the earlier Stanford linear accelerator.

Lastly, one of our papers devotes considerable attention to identifying the factors that have structured the performance of CERN accelerators. It is therefore incorrect to say that we offer no explanation for the improvement over recent years.

BEN MARTIN JOHN IRVINE

Science Policy Research Unit,

University of Sussex,

Falmer, Brighton, Sussex BNI 9RF, UK

\section{Irish students}

SIR - We were surprised by your statement (18 October p.592) under the heading "Irish disunity" to the effect that "Roman Catholic students from Ulster tend to seek higher education south of the border when (sic) they are welcomed as if Irish".

This statement is patently false and could be unwittingly damaging. Although the Queen's University of Belfast, being completely non-sectarian, does not keep statistics of students' religions, it is common knowledge that the proportion of Catholic students at Queen's easily exceeds the proportion of Catholics in the population of Northern Ireland as a whole. The several thousands of Catholic students at Queen's alone, apart altogether from those in the non-sectarian University of Ulster, constitute a group at least four times larger than the total number of all Northern Ireland students who attend universities in the Irish Republic.

The Queen's University of Belfast,

I.D. STRAHAN Belfast BT7 INN, UK 